\title{
Rapid identification of chloroplast haplotypes using High Resolution Melting analysis
}

\author{
XIAO-DONG DANG,${ }^{*}$ COLIN T. KELLEHER,+ EMMA HOWARD-WILLIAMS,${ }^{*}+$ and CONOR V. \\ MEADE* \\ *Molecular Ecology Laboratory, Department of Biology, National University of Ireland Maynooth, Co. Kildare, Ireland, +DBN Plant \\ Molecular Laboratory, National Botanic Gardens, Glasnevin, Dublin 9, Ireland
}

\begin{abstract}
We have evaluated High Resolution Melting (HRM) analysis as a method for one-step haplotype identification in phylogeographic analysis. Using two adjoined internal amplicons (c. 360 and $390 \mathrm{bp}$ ) at the chloroplast rps16 intron (c. $750 \mathrm{bp}$ ) we applied HRM to identify haplotypes in 21 populations of two European arctic-alpine herb species Arenaria ciliata and Arenaria norvegica (Caryophyllaceae). From 446 accessions studied, 20 composite rps16 haplotypes were identified by the melting-curve protocol, 18 of which could be identified uniquely. In a comparative sensitivity analysis with in silico PCR-RFLP, only seven of these 20 haplotypes could be identified uniquely. Observed in vitro experimental HRM profiles were corroborated by in silico HRM analysis generated on $\mathrm{uMelt}^{\mathrm{SM}}$. In silico mutation analysis carried out on a $360 \mathrm{bp}$ wild-type rps16I amplicon determined that the expected rate of missed single-nucleotide polymorphisms (SNP) detection in vitro was similar to existing evaluations of HRM sensitivity, with transversion SNPs being more likely to go undetected compared to transition SNPs. In vitro HRM successfully discriminated between all amplicon templates differing by two or more base changes (352 cases) and between 11 pairs of amplicons where the only difference was a single transition or transversion SNP. Only one pairwise comparison yielded no discernable HRM curve difference between haplotypes, and these samples differed by one transversion (C/G) SNP. HRM analysis represents an untapped resource in phylogeographic analysis, and with appropriate primer design any polymorphic locus is potentially amenable to this single-reaction method for haplotype identification.
\end{abstract}

Keywords: angiosperms, conservation genetics, phylogeography, population genetics-empirical, speciation

Received 16 February 2012; revision received 27 April 2012; accepted 4 May 2012

\section{Introduction}

An issue of ongoing concern in haplotype-based phylogeographic analysis is that polymorphism levels in targeted field populations may be underestimated due to insufficient sampling, as rare haplotypes can potentially go unrepresented where less than ten individuals per population are analysed (Bettin et al. 2007; Teacher et al. 2009), and biased or incorrect conclusions can thus emerge due to insufficiency of data (Petit et al. 2005). While the commonly used low-cost technique PCR-RFLP (Taberlet et al. 1998) can be applied to large quantities of samples, it cannot detect point mutations that are not covered by restriction enzyme cut sites. Alternatively, exhaustive sequencing of all accession samples in a given analvsis is in most cases cost-prohibitive. Thus a more

Correspondence: Conor Meade, Fax: +353-1-7083845;

E-mail: conor.v.meade@nuim.ie efficient low-cost method with increased sensitivity to small polymorphic differences would assist greatly in detecting both common and under-represented haplotypes from the field.

High Resolution Melting (HRM) analysis has emerged as a powerful method for genotype identification in short DNA amplicons and currently is applied most often in biomedical analyses (Wittwer 2009). HRM is based on real-time PCR (polymerase chain reaction) techniques, where duplex DNA-binding fluorescent dyes, e.g. LC Green and SYBR Green I, are incorporated into PCR reactions to monitor the progress of DNA amplification (Wittwer et al. 1997). The melting process involves the programmed increase of temperature to dissociate the amplified double-strand DNA amplicons, leading to a decrease in the strength of detected fluorescent signals. The melting curve is thus obtained by plotting the decline of fluorescence against real-time increase in temperature (Fig. 1). As the shape of the melting curve and the 
(a)

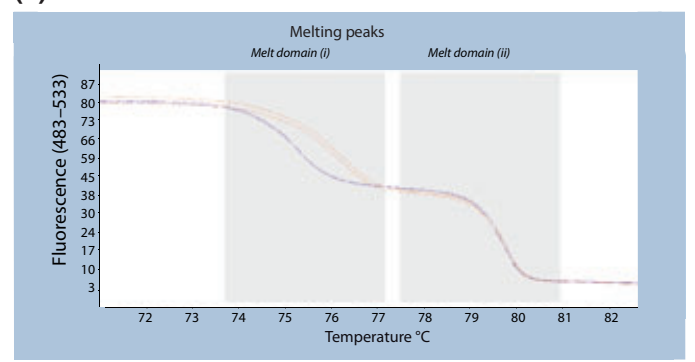

(b)

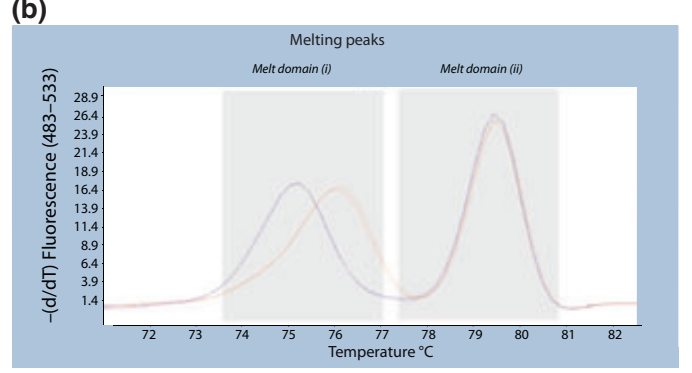

(c)

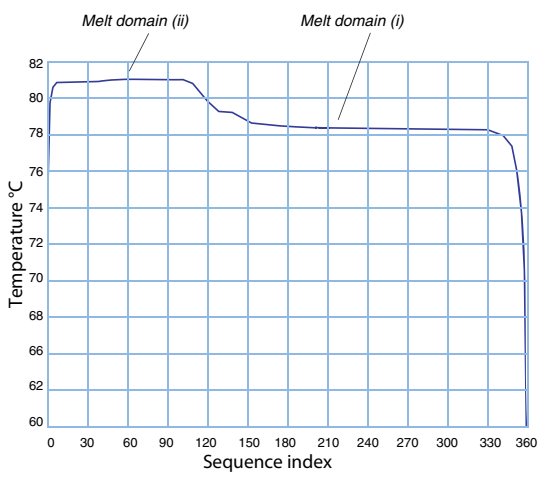

Fig. 1 Derivation of melting peak data. (a) In vitro melt-curve profile for two rps16I amplotypes recording sequential decline in fluorescence caused by dissociation of double-stranded PCR amplicons with increasing temperature. Maximum declines are evident in melting domains (i) and (ii). (b) Calculated melting peaks for these profiles where peak amplitudes indicate temperature point of maximum amplicon dissociation. In this example for rps16I, the two principal melting domains give rise to two distinct High Resolution Melting peaks (i and ii). [generated on Roche LC480 system]. (c) Modelled in silico dissociation behaviour of rps16I amplicon by sequence position and temperature, indicating the template location of two principal melt domains (i and ii). [generated via HRM simulation on $u M$ Melt ${ }^{\text {SM }}$ ].

temperature of maximum dissociation rate (the melting peak, $T_{\mathrm{m}}$, Fig. 1) are determined by the sequence content of the DNA amplicon involved, melting curve analysis is increasingly used in the identification of variation in sequence content of PCR amplicons (Ririe et al. 1997), including studies in population biology (Mader et al. 2010; Smith et al. 2010), where the exact sequences and expected identities of the studied template alleles have been predefined before HRM analysis is applied.

High Resolution Melting analysis has recently been used to detect unexpected mutations in for example lineage screening in perennial ryegrass breeding (Studer et al. 2009), and this advantage points to the potential utility of HRM in phylogeographic analysis where neither the number nor sequence identities of alleles at a particular DNA locus are known.

A key consideration however is the technical limits that apply to HRM, as the size and specific nucleotide content of amplicons influences the discriminating ability of HRM analysis, due to the complex physical-chemical mechanisms of DNA duplex denaturation (Ririe et al. 1997; Wittwer et al. 2003). In general, for a single point mutation between two genotypes the divergence in $T_{\mathrm{m}}$ values becomes greater when less flanking DNA is included in the targeted amplicon, thus small fragments are preferred for many HRM applications because HRM analysis has less sensitivity in discriminating between larger amplicons (Liew et al. 2004). In an experimental evaluation of HRM sensitivity across a range of amplicon size classes, identification of one single-nucleotide polymorphisms (SNP) between otherwise homologous amplicons was achievable in $100 \%$ of cases for product $<300 \mathrm{bp}$ in length, but less reliable between 400 and $1000 \mathrm{bp}$ (Reed \& Wittwer 2004). In phylogeographic analysis, however, larger DNA regions (300-1000 bp) are routinely sequenced to identify multiple nucleotide polymorphisms (Shaw et al. 2005, 2007), one advantage of which is obtaining extensive sequence information with only one pair of primers for each locus. If HRM analysis is to be performed with these loci, internal primers are thus needed to amplify two or more shorter amplicons covering the whole length of the given locus. The challenge for amplicon design is to seek a balance between HRM resolution and sequence coverage.

High Resolution Melting is known to have sensitivity limits for different classes of point mutation between amplicons; $\mathrm{A} / \mathrm{T}$ substitutions are generally regarded as the most difficult to identify (Reed \& Wittwer 2004) though G/C substitutions can also be problematic (Liew et al. 2004), and these difficulties persist for larger amplicons. Alternately one useful attribute of larger amplicons is the possibility of more than one $T_{\mathrm{m}}$ melting peak being generated per amplicon, for example, fragments $>c .200 \mathrm{bp}$ can have two or more melting domains, and these additional $T_{\mathrm{m}}$ peaks provide elevated sensitivity for template polymorphisms (Reed \& Wittwer 2004; 
Vossen et al. 2009; Wittwer 2009). The number of melting domains within any given amplicon is determined by its sequence composition, thus some capacity to run an a-priori evaluation of amplicon design and performance would be a key tool for HRM-based haplotype detection in phylogeographic studies.

This tool has recently appeared with the development in silico HRM modelling. In silico simulation methods have been compiled into the web-based software, uMelt $^{\mathrm{SM}}$ (Dwight et al. 2011), and with this software it is possible to use a limited number of known sequences as a basis for evaluating the likely sensitivity of HRM for a given range of haplotypes, reviewing the performance of in vitro reactions compared to empirical expectations, and proofing the likely HRM sensitivity for certain neutral substitutions within a given amplicon. Taken together these in silico applications can assist greatly in helping to optimize stand-alone in vitro analyses.

In a general sense, and bearing in mind the need to clarify the various analysis limits associated with HRM, the low unit cost and high resolution of the method point to the potential benefit of a usable HRM protocol for phylogeographic analysis. In the present work we have set out to establish the utility of HRM analysis as a haplotype screening method in plant phylogeography; in this case by analysing chloroplast diversity in populations of two closely related cold-tolerant herbaceous species, Arenaria ciliata L. and Arenaria norvegica Gunnerus (Caryophyllaceae) which have disjunct distributions across Europe. In this context our objectives have been three-fold: (i) to evaluate the limitations of HRM in terms of sensitivity, repeatability and consistency with regard to the identification of haplotypes at a polymorphic chloroplast DNA locus; (ii) to validate the efficacy of HRM in identifying the range of chloroplast haplotypes that are present in a large biogeographically diverse sample set and (iii) to determine the utility of in silico HRM modelling as an aid to in vitro HRM experiments and as a tool for visualizing the sensitivity limits of HRM with respect to single point mutations between haplotypes.

\section{Materials and methods}

\section{Materials}

The two target species, Arenaria ciliata L. and Arenaria norvegica Gunnerus, are perennial herbs of the family Caryophyllaceae (Angiosperm Phylogeny Group III 2009). A. ciliata is an arctic-alpine calcicole herb with several subspecies widely distributed in the high mountains of Europe, with isolated populations in Scandinavia and northwest Ireland. A. norvegica is a quasi-arctic species occurring in Norway, Iceland, the Shetland and Faroe Islands, Britain and Ireland (Jalas \& Suominen 1983;
Tutin et al. 1993). The two species are closely related taxonomically (Wyse Jackson \& Parnell 1987), and while both are associated with shallow poorly formed soil on exposed limestone habitats, they are not known to co-occur at any single location. For this study we used 15 populations of $A$. ciliata from throughout Europe and six populations of A. norvegica from Ireland, Britain and Iceland, totalling 446 individual accessions and a median population sample size of 26 (Table S1, Supporting information).

\section{DNA preparation and initial assays}

Total genomic DNA was extracted from silica-dried leaf tissue using a modified CTAB protocol (Doyle \& Doyle 1987) and dissolved in de-ionized $\mathrm{H}_{2} \mathrm{O}$. The target locus for haplotype identification was selected based on comparative sequence analysis of selected A. ciliata and $A$. norvegica accessions at five non coding chloroplast loci prompted by Shaw et al. $(2005,2007)$; rpl16, rps16, trnStrnG, trnT-trnL and rpl32-trnL. Primer sequences and corresponding PCR programmes for all the tested loci were as per Shaw et al. $(2005,2007)$ and primers were synthesized by Applied Biosystems BV. PCR was performed on a PTC-200 Thermal Cycler (MJ Research) with GoTaq $^{\circledR}$ Flexi DNA polymerase/buffer system (Promega). Reaction volume was $25 \mu \mathrm{L}$ containing $1 \times$ buffer, $2 \mathrm{~mm} \mathrm{MgCl}, 0.2 \mathrm{~mm}$ each of the four dNTPs, $0.4 \mu \mathrm{M}$ each of the forward and reverse primers, $1 \mu \mathrm{L}$ of DNA template (ranging from 20 to 200 ng DNA), 0.5 U Taq polymerase and de-ionized water. PCR product was screened on a $1.5 \%$ agarose gel using SYBR Safe DNA gel stain (Invitrogen). Confirmed PCR products were purified using the mi-PCR Purification Kit (Metabion) and sequenced by Eurofins MWG Operon. Sequencing primer sets were as used for initial PCR. Completed sequences were aligned using BioEdit 7.0.9 (Hall 1999) and compared between samples from different populations. Selection of optimal loci for HRM analysis was based on evident inter population variation and outline size of primed PCR amplicons.

\section{Primer design and locus selection for High-Resolution Melting analysis}

The five tested loci varied in size between 640 and $1350 \mathrm{bp}$ in length, thus internal primers were necessary to divide each of the loci into $c$. 3-400 bp amplicons more suitable for HRM. Primer design rested on two criteria, (i) internal primers must bind to conserved regions of the DNA locus to ensure broad intra-specific sensitivity and (ii) as few internal primers as possible were sought for each locus to maximize the efficiency of HRM analysis. Internal primers were designed with AlleleID 7 (Premier 
Biosoft International) using its SYBR ${ }^{\circledR}$ Green Design function. Cross Species Design was conducted with aligned locus sequences from different populations of $A$. ciliata and $A$. norvegica. For primer searching, the target amplicon length was set between 250 and $400 \mathrm{bp}$, the length of primers was set between 18 and $30 \mathrm{bp}$ and the primer Ta was set at $55.0 \pm 5.0^{\circ} \mathrm{C}$. Considering the requirements for appropriate amplicon lengths, optimal coverage of polymorphic sites and conservation of sequence at primer sites, rps16 was finally selected for this analysis with two pairs of internal primers (rps16I: forward 5'-ATG CTC TTG ACT CGA CAT CTT-3', reverse 5'-GGG TTT AGA CAT TAC TTC GTT GAT T-3', amplicon size c. 360 bp; rps16II: forward 5'-AAG TAA TGT CTA AAC CCA ATG ATT CAA-3', reverse 5'-CGT ATA GGA AGT TTT CTC CTC GTA-3', c. 390 bp; the two internal amplicons are adjacent with 17 bp overlap, and cover $c .750 \mathrm{bp}$ of the rps16 intron).

\section{High-Resolution Melting analysis: in vitro protocols}

Real-time PCR protocols were conducted in Roche LightCycler ${ }^{\circledR} 480$ (LC480) Multiwell plates (96-well white) on the LC480 instrument (Hoffman-La Roche, Basel, Switzerland) using the LC480 HRM Master Mix reagent kit (Roche). Real-time PCR programmes and reaction mixes were optimized to generate the required quantities of amplicon necessary for full melting analysis (Table 1). Following DNA quantification of stock sample aliquots using a Nanodrop 1000 spectrophotometer (Thermo Scientific) DNA template samples were diluted to 20-30 ng/ $\mu$ L. HRM analysis was carried out in singlepopulation batches, with the aim of managing inter individual and inter plate errors arising from variation of template concentration and quality across samples from different population extractions. Only population samples IT2, IT3 and FR1 were assayed with other populations because of their small sampling sizes. Each individual accession from each population (total 446 samples) was run in duplicate or triplicate for HRM analysis, depending on the total sample size in the run. Each real-time PCR reaction was conducted in a $15 \mu \mathrm{L}$ final volume containing $7.5 \mu \mathrm{L}$ of the Taq enzyme mix (No. 1 reagent from the Roche HRM Master kit containing Taq polymerase, dNTPs, buffer system and saturating dsDNA binding dye), $1.5 \mu \mathrm{L}$ of $25 \mathrm{mM} \mathrm{MgCl}_{2}$ solution (No. 2 reagent from the Roche HRM Master kit, final $\mathrm{Mg}$ concentration $2.5 \mathrm{~mm}$ ), $1.5 \mu \mathrm{L}$ of primer mix (final concentration $1 \mu \mathrm{M}$ each), $3.5 \mu \mathrm{L}$ of de-ionized water (No. 3 reagent from the Roche HRM Master kit) and $1 \mu \mathrm{L}$ of DNA template (20-30 ng). Fluorescence values for each sample replicate in each PCR cycle were recorded through the SYBR Green (483-533 nm) channel using the default LC480 data acquisition settings.

\section{Interpretation and analysis of High Resolution Melting curve profiles}

Peak $T_{\mathrm{m}}$ Calling Analysis was performed after each realtime PCR reaction run using the LC480 Software (release 1.5.0 SP3, Version 1.5.0.39) based on which two clear melting peaks were revealed for amplicon rps16I (Fig. 1), while one prominent clear peak, named $T_{\mathrm{m} 3}$, and a less prominent lower temperature shoulder $\left(T_{\mathrm{mX}}\right)$ were revealed for amplicon rps16II (Fig. 2D). $T_{\mathrm{m}}$ values for the obtained melting peaks were given initially by automatic $T_{\mathrm{m}}$ calculation under 'SYBR Green I Format' where the number of 'Maximal Peaks' was set as '2 or less' by default, and these values were manually adjusted to mark the temperatures where the melting peaks were at their maximum heights.

Two or three replicates were used to validate the consistency of the recorded rps16I and II amplicon melting profiles for each analyzed accession, depending on the sample analysis run. Each new amplicon type recorded for rps16I and II was assigned an identity (which we have

Table 1 Cycle settings for real-time PCR high resolution melt analysis of amplicons rps16I and II on Roche LightCycler ${ }^{\circledR} 480$ system

\begin{tabular}{|c|c|c|c|c|c|c|}
\hline $\begin{array}{l}\text { Stage of } \\
\text { High Resolution } \\
\text { Melting } \\
\text { programme }\end{array}$ & $\begin{array}{l}\text { Target } \\
\text { temperature } \\
\left({ }^{\circ} \mathrm{C}\right)\end{array}$ & $\begin{array}{l}\text { Duration } \\
\text { (mm:ss) }\end{array}$ & $\begin{array}{l}\text { Ramp rate } \\
\left({ }^{\circ} \mathrm{C} / \mathrm{s}\right)\end{array}$ & $\begin{array}{l}\text { Number of } \\
\text { cycles }\end{array}$ & Acquisitions $/{ }^{\circ} \mathrm{C}$ & $\begin{array}{l}\text { Analysis } \\
\text { mode }\end{array}$ \\
\hline \multirow[t]{2}{*}{ Pre incubation } & 95 & $10: 00$ & 4.4 & 1 & - & \\
\hline & 95 & $00: 15$ & 4.4 & & - & \\
\hline \multirow[t]{3}{*}{ Amplification } & 60 & $00: 15$ & 2.2 & 30 & - & Quantification \\
\hline & 72 & $00: 25$ & 1 & & Single & \\
\hline & 95 & 00:05 & 4.4 & & - & \\
\hline \multirow[t]{2}{*}{ Melting } & 65 & 01:00 & 2.2 & 1 & - & $\begin{array}{l}\text { Melt curve } \\
\text { generation }\end{array}$ \\
\hline & 97 & - & 0.01 & & 50 & \\
\hline Cooling & 40 & 30 & 1.5 & 1 & & \\
\hline
\end{tabular}


(a)

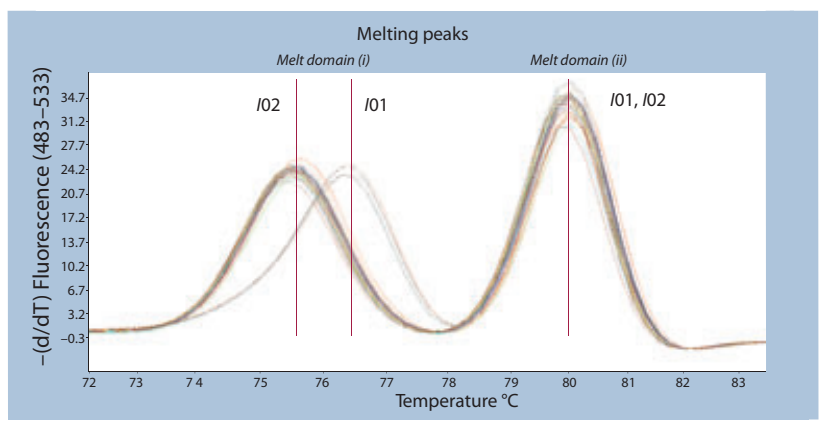

(b)

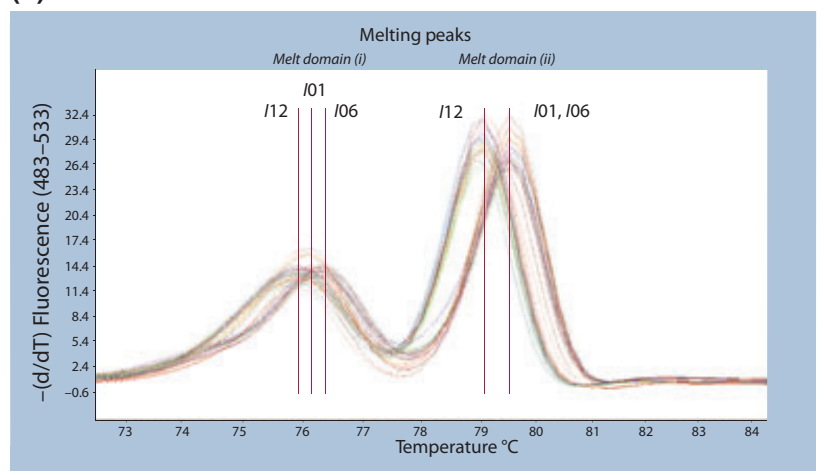

(c)

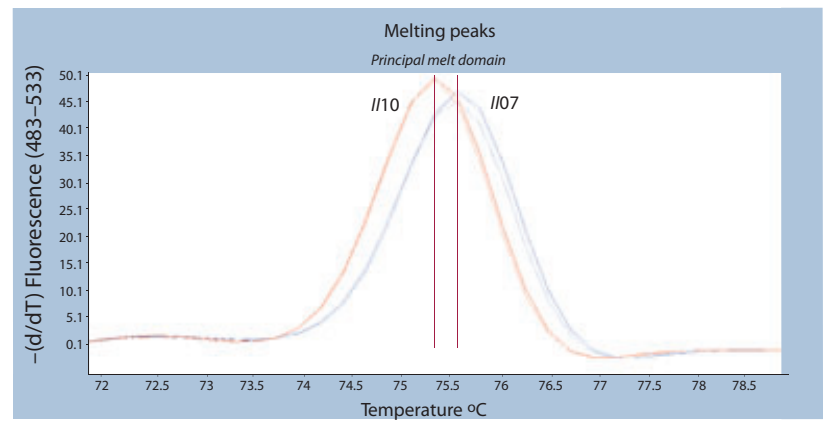

(d)

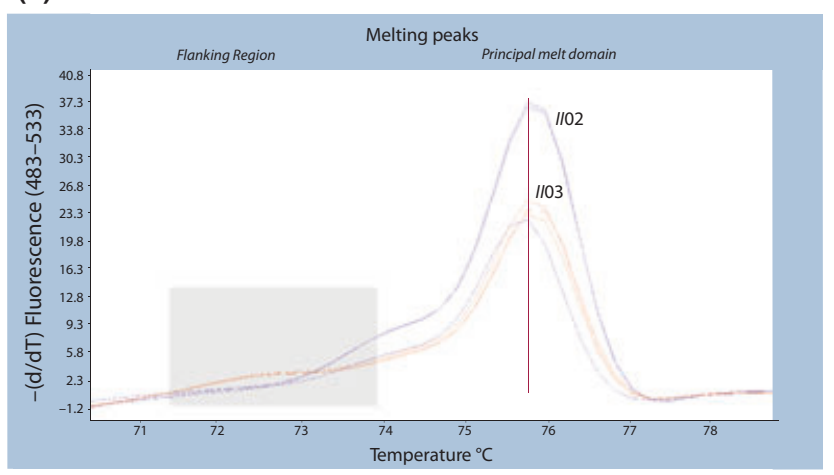

Fig. 2 Sensitivity of in vitro High Resolution Melting to haplotype variation. (a) Melting peak data for amplicon rps16I (c. $360 \mathrm{bp}$ ) in an Irish population of 30 Arenaria ciliata individuals showing amplotypes $I 01$ and $I 02$ with distinct $T_{\mathrm{m} 1}$ values, arising from one single-nucleotide polymorphisms (SNP), one $6 \mathrm{bp}$ indel and one $7 \mathrm{bp}$ indel difference between templates in melt domain (i) (detailed in Table 2). (b) melting peak data for amplicon rps16I (c. $360 \mathrm{bp}$ ) in an Austrian population of 25 A. ciliata individuals revealing 3 amplotypes I01, I06 and $I 12$ with distinct $T_{\mathrm{m} 1}$ and $T_{\mathrm{m} 2}$ peak values, arising from 6 distinct SNP differences in melt domains (i) and (ii) (detailed in Table 2). (c) Melting peak data for amplicon rps16II (c. 390 bp) showing amplotypes II07 (in blue) and II10 (in red) that deviate by a single C/T SNP in the principal melt domain (detailed in Table 3). (d) The $T_{\mathrm{m} 3}$ flanking region ' $T_{\mathrm{mx}}$ ' in the rps16II amplicon provides additional discriminatory value, in this case distinguishing amplotypes II02 [purple, sample Ir1.25] from II03 [orange, sample Ir2.14] which differ by a $13 \mathrm{bp}$ indel that flanks the principal melt domain (detailed in Table 3).

termed 'amplotype'), e.g. I01, I02 or II01, II02 etc. Final $T_{\mathrm{m}}$ values were manually validated for each accession based on the standardized curves of the replicates for each amplicon. Two additional analyses were carried out to validate the consistency of the method; (i) single-plate analysis of multiple accessions of one amplotype drawn from several different populations, to evaluate the relative variation in HRM profiles associated with populationspecific factors and (ii), full-plate replicates comprising 60 individual HRM analyses of a single sample accession, to evaluate well-to-well variation across the plate.

Amplotype confirmation for each sample was carried out using a standard protocol. Within each run batch, samples were first grouped into different hypothesized amplotypes based on their validated melting curves $\left(T_{\mathrm{m}}\right.$ values). After initial analysis runs (Table 1), variation of $\geq 0.2{ }^{\circ} \mathrm{C}$ in $T_{\mathrm{m}}$ was considered the likely level of divergence which would be evident between variant amplotypes, with the proviso that ongoing analysis might alter this working assumption (no guidance was available from the literature on haplotype $T_{\mathrm{m}}$ divergence in amplicons larger than $150 \mathrm{bp}$ ). Sample profiles that differed by $\geq 0.2{ }^{\circ} \mathrm{C}$ at any of the three $T_{\mathrm{m}}$ peaks or the shoulder region $\left(T_{\mathrm{mX}}\right)$ beside rps16II $T_{\mathrm{m} 3}$ were regarded as having potentially distinct amplotypes, the difference between putative amplotypes termed ' $\Delta \mathrm{Tm}$ '.

For each discrete $T_{\mathrm{m}}$ group within each population the amplotype sequence identity was obtained. Where within-group $T_{\mathrm{m}}$ variance was evident but at $<0.1^{\circ} \mathrm{C}$, two individuals were randomly selected from this group to be sequenced over the whole rps16 region. When within-group variance was between 0.1 and $0.2{ }^{\circ} \mathrm{C}$, the individuals with the lowest and the highest $T_{\mathrm{m}}$ values were chosen to be sequenced to confirm rps16 sequence composition. If different amplotypes were detected within a pre classified group in the latter manner, one or two additional samples from each new subgroup were chosen for sequencing to confirm the revised amplotype groupings. To control inter population error, the sampling protocol required that in each population a minimum of two replicates of each putative amplotype were sequenced, even where the same melting curve profile 
had been encountered in another population. Each putative amplotype for both rps16I and II was sequenced over the full c. $750 \mathrm{bp}$ length of rps16, and following comparative alignment of these sequences, the final compilation of composite rps16 haplotypes was completed.

Analysis runs were carried out on the central 60 wells of the 96-well plate to minimize the possibility of edgeeffect variation. In total some 2000 individual HRM reactions for the two rps16 loci were carried out over 38 runs, covering all 446 individual sample accessions and validation checks/re-runs, where necessary.

In addition to collation of recorded $T_{\mathrm{m} 1}, T_{\mathrm{m} 2}, T_{\mathrm{m} 3}$ and $T_{\mathrm{mX}}$ shoulder values for each composite haplotype, a pairwise matrix of inter haplotype $\Delta T_{\mathrm{m}}$ values was also created for each of these peaks to provide an overview of expected degree Celsius divergence between all haplotypes that could potentially occur in a single population sample. To further facilitate evaluation of the correlation (if any) between $\Delta T_{\mathrm{m}}$ and evolutionary distance between haplotypes (and in particular the extent to which closely related haplotypes can be discriminated using their pairwise $\Delta T_{\mathrm{m}}$ ) the $\Delta T_{\mathrm{m}}$ matrix was supplemented by an identically composed pairwise matrix of Tajima-Nei genetic distance D (Tajima \& Nei 1984) between haplotypes, based on sequence composition. A Mantel test (Mantel 1967) was used for correlation analysis between these matrices, with the ade4 package (Thioulouse et al. 1997) within the R software 2.12.2 (R Development Core Team 2011).

\section{High-Resolution Melting analysis: in silico simulation}

Evaluation of the utility of in silico HRM modelling as a support for in vitro HRM analysis. For all the amplotypes identified in the in vitro analysis, obtained sequences were uploaded to $\mathrm{uMelt}^{\mathrm{SM}}$ (Dwight et al. 2011), and subjected to in silico simulation of the melting process. uMelt $^{\mathrm{SM}}$ simulations applied the thermodynamic settings of Huguet et al. (2010), with the temperature range of melting set between 65 and $95^{\circ} \mathrm{C}$ and resolution set to maximal resolution at $0.1{ }^{\circ} \mathrm{C}$. Concentration of free $\mathrm{Mg}^{2+}$ was set at $2.5 \mathrm{~mm}$ to be consistent with in vitro analysis, and DMSO was set at $10 \%$ to minimize the difference between the absolute in silico and in vitro $T_{\mathrm{m}}$ values. Derived values for $T_{\mathrm{m} 1}, T_{\mathrm{m} 2}, T_{\mathrm{m} 3}$ and the $T_{\mathrm{m} 3}$ shoulder $\left(T_{\mathrm{mX}}\right)$ were recorded for each unique amplotype, and as carried out for the in vitro data, pairwise inter amplotype matrices of $\Delta T_{\mathrm{m}}$ values at each $T_{\mathrm{m}}$ peak were created. As all in vitro data, especially the estimated optimal $T_{\mathrm{m}}$ values for individual amplotypes, is subject to experiment-specific environmental factors, some divergence between observed absolute in vitro and in silico $T_{\mathrm{m}}$ values was expected for each individual amplotype (Fig. 1B,C). Thus to establish whether comparative analysis of in silico HRM data could in this case be used to support in vitro work, the underlying pattern of $T_{\mathrm{m}}$ estimation in the two methods was analysed. A Mantel test-based correlation analysis was carried out between in vitro and in silico data in two ways: (i) direct comparison of the calculated amplotype $T_{\mathrm{m}}$ values from in vitro and in silico analysis respectively, and (ii) comparison of pairwise inter amplotype $\Delta T_{\mathrm{m}}$ matrices derived from in vitro and in silico analysis (Mantel 1967).

Sensitivity of HRM to single-substitution mutations between amplotypes: in silico evaluation of single substitutions in a wild-type template. In order to appraise inter haplotype SNP variation in recently diverged matrilines, it is necessary to understand the sensitivity limitations that may apply to HRM in the detection of single base differences between amplicons. Using locus rps16I, the sequence of haplotype rps16I01 (amplicon $352 \mathrm{bp}$ in length) was selected as a wild type template to generate single substitutions on all possible nucleotide sites within the amplicon outside the primer-binding sites (sites 1-21 and 328-352). All of these mutant amplotypes were inputted to $\mathrm{uMelt}^{\mathrm{SM}}$ to generate their melting peaks and corresponding $T_{\mathrm{m}}$ values. As the highest resolution of uMelt $^{\mathrm{SM}}$ is $0.1{ }^{\circ} \mathrm{C}$, if the $\Delta T_{\mathrm{m}}$ between two haplotypes is $<0.1{ }^{\circ} \mathrm{C}$, the two amplotypes were considered to be indistinguishable by HRM analysis. This approach facilitated an in silico evaluation of the theoretical missing-detection rate for $\mathrm{A} / \mathrm{T}$ and $\mathrm{C} / \mathrm{G}$ mutations in in vitro experiments.

\section{Comparison of HRM performance against in silico RFLP}

To evaluate the performance of HRM against PCR-RFLP, an in silico RFLP analysis was undertaken on the composite haplotypes identified using HRM in this study. DNA sequences from each haplotype were subjected to in silico digestions using the NEBcutter software (Vincze et al. 2003). Following, this enzyme combinations were selected to evaluate the in silico RFLP profiles using the Bioperl tool DistinctiEnz (http://www.bioinformatics. org/ docreza/rest_html/help_DistinctiEnz.htm). Among the trialled set of enzyme combinations the most informative was a combination of ApoI (6-base cutter) with AluI (4-base cutter).

\section{Results}

Haplotype detection in the sampled populations of Arenaria ciliata and Arenaria norvegica

Within the 446 individual samples from 21 populations of $A$. ciliata and $A$. norvegica, 14 amplotypes of rps16I and 14 amplotypes of rps16II were detected. When all 28 
putative amplotypes were aligned over the full length of rps16I and $I I$, a total of 20 composite haplotypes were identified, 18 of them for A. ciliata and two for A. norvegica (Tables 2-4). The $T_{\mathrm{m}}$ values shown in Table 4 are adjusted mean values that incorporate plate-to-plate $T_{\mathrm{m}}$ variations in the inter plate reference samples. These are validated by additional HRM analysis of selected haplotype individuals, either single accessions analysed in 60 replicate HRM reactions on the same plate, to determine well-to-well consistency, or multiple individuals of the same amplotypes drawn from different populations and re-run on the same single plate, to determine inter population and inter plate consistency. Within the replicate analyses of single accessions, total variation in observed $T_{\mathrm{m}}$ ranged between 0.04 and $0.16{ }^{\circ} \mathrm{C}$, while total variation between replicates of the same amplotypes drawn from different populations ranged between 0.12 and $0.23{ }^{\circ} \mathrm{C}$, based on three replicates of each amplotype accession from each population. Recorded haplotypes differed at multiple nucleotide sites both by point mutations and insertion-deletion events (Table 2 and 3), and in a maximum likelihood phylogenetic analysis of $A$. ciliata and several sister species, the observed rps16 haplotypes all emerged within an A. ciliata clade with $100 \%$ bootstrap support (Fig. S1, Supporting information). In every case it was possible to assign individual samples from each population to a validated composite haplotype identity (Table 4).

\section{Rps16I data}

All but two amplotypes of rps16I were readily distinguishable from one another by their combined $T_{\mathrm{m} 1}$ and $T_{\mathrm{m} 2}$ values (Fig. $2 \mathrm{~A}, \mathrm{~B}$ ), including seven cases where these $T_{\mathrm{m}}$ differences were based on a single SNP between amplotype templates. Amplotypes rps16I04 and I11 differed greatly in sequence composition (by five substitutions and one 6-bp indel) but displayed the same $T_{\mathrm{m} 1}$ and $T_{\mathrm{m} 2}$ values. These amplotypes are seen to be endemic to populations in Ireland and Spain, respectively, however by sequencing at least two replicates of each putative amplotype in each population, incorrect assignment of amplotype identity in the initial population analysis was avoided. In addition the composite rps16 sequence of both amplotypes differed in $\operatorname{rps} 16 I I$ and respective $T_{\mathrm{m} 3}$ values were clearly distinct, providing a valid HRM diagnostic. Table 2 details the template differences between amplotypes $I 01$ and $I 02$ and between I01, I06 and I12 that give rise to the distinct HRM profiles and $T_{\mathrm{m} 1} / T_{\mathrm{m} 2}$ values for each as shown in Fig. 2A,B respectively.

Table 2 Polymorphic sites and principal melting domains among 14 rps16I amplotypes identified by High Resolution Melting (HRM) analysis

\begin{tabular}{|c|c|c|c|c|c|c|c|c|c|c|c|c|c|c|c|c|c|c|}
\hline \multirow[b]{3}{*}{ Amplotype } & \multicolumn{18}{|c|}{ Base position } \\
\hline & \multicolumn{5}{|c|}{ Melt domain (ii) } & \multicolumn{13}{|c|}{ Melt domain (i) } \\
\hline & 29 & 49 & 93 & 113 & $124-129$ & 160 & 166 & 217 & $231-237$ & 241 & 245 & 246 & 252 & 290-295 & 296 & 306 & 314 & $321-325$ \\
\hline IO1 & G & $\mathrm{T}$ & $\mathrm{C}$ & $\mathrm{A}$ & AAAGAA & G & G & G & ATATATC & $\mathrm{T}$ & $\mathrm{A}$ & $\underline{C}$ & $\mathrm{C}$ & - & $\mathrm{C}$ & $\mathrm{T}$ & G & \\
\hline $\mathrm{IO} 2$ & $\mathrm{G}$ & $\mathrm{T}$ & $\mathrm{C}$ & A & AAAGAA & G & G & G & $\bar{\square}$ & $\mathrm{T}$ & A & $\underline{\overline{\mathrm{A}}}$ & $\mathrm{C}$ & $\underline{\text { TTATAA }}$ & $\mathrm{C}$ & $\mathrm{T}$ & G & $\longrightarrow$ \\
\hline IO3 & G & $\mathrm{T}$ & $\mathrm{C}$ & $\mathrm{A}$ & AAAGAA & G & G & G & ATATATC & $\mathrm{T}$ & $\mathrm{A}$ & $\overline{\mathrm{C}}$ & $\mathrm{C}$ & & $\mathrm{C}$ & $\mathrm{T}$ & G & TTTTT \\
\hline $\mathrm{IO} 4$ & G & $\mathrm{T}$ & $\mathrm{C}$ & $\mathrm{A}$ & $\longrightarrow$ & G & G & G & ATATATC & $\mathrm{T}$ & A & $\mathrm{C}$ & $\mathrm{C}$ & & $\mathrm{C}$ & $\mathrm{T}$ & G & \\
\hline IO5 & G & $\mathrm{T}$ & $\mathrm{C}$ & $\mathrm{C}$ & AAAGAA & G & $\mathrm{T}$ & G & & $\mathrm{T}$ & $\mathrm{A}$ & $\mathrm{A}$ & $\mathrm{C}$ & & $\mathrm{C}$ & $\mathrm{T}$ & G & \\
\hline IO6 & G & $\mathrm{T}$ & $\mathrm{C}$ & A & AAAGAA & G & G & G & ATATAGC & C & A & $\mathrm{A}$ & C & & C & $\mathrm{T}$ & C & \\
\hline IO7 & G & G & $\mathrm{C}$ & A & AAAGAA & G & G & G & ATATAGC & C & $\mathrm{A}$ & $\mathrm{A}$ & C & & $\mathrm{C}$ & $\mathrm{T}$ & $\mathrm{C}$ & \\
\hline IO8 & $\mathrm{A}$ & $\mathrm{T}$ & $\mathrm{C}$ & A & AAAGAA & G & G & G & ATATATC & $\mathrm{C}$ & $\mathrm{C}$ & $\mathrm{A}$ & G & & $\mathrm{C}$ & $\mathrm{T}$ & $\mathrm{C}$ & \\
\hline IO9 & G & $\mathrm{T}$ & $\mathrm{C}$ & A & AAAGAA & G & $\mathrm{T}$ & G & & $\mathrm{T}$ & A & A & $\mathrm{C}$ & & $\mathrm{C}$ & $\mathrm{T}$ & G & \\
\hline$I 10$ & G & $\mathrm{T}$ & $\mathrm{T}$ & A & AAAGAA & G & $\mathrm{T}$ & G & & $\mathrm{T}$ & A & A & $\mathrm{C}$ & & $\mathrm{C}$ & $\mathrm{T}$ & G & \\
\hline I11 & G & $\mathrm{T}$ & $\mathrm{C}$ & A & AAAGAA & $\mathrm{T}$ & G & G & ATATAGC & $\mathrm{C}$ & A & A & $\mathrm{C}$ & & $\mathrm{C}$ & $\mathrm{T}$ & $\mathrm{C}$ & \\
\hline$I 12$ & A & $\mathrm{T}$ & $\mathrm{C}$ & $\mathrm{A}$ & AAAGAA & G & G & G & ATATATC & $\mathrm{C}$ & $\mathrm{C}$ & A & G & & $\mathrm{T}$ & $\mathrm{T}$ & $\mathrm{C}$ & \\
\hline$I 13$ & G & $\mathrm{T}$ & $\mathrm{C}$ & A & AAAGAA & G & $\mathrm{T}$ & $\mathrm{T}$ & $\longrightarrow$ & $\mathrm{T}$ & A & A & C & $\longrightarrow$ & $\mathrm{C}$ & G & G & \\
\hline$I 14$ & G & $\mathrm{T}$ & $\mathrm{C}$ & $\mathrm{A}$ & AAAGAA & G & G & G & & $\mathrm{T}$ & $\mathrm{A}$ & A & $\mathrm{T}$ & TTATAA & $\mathrm{C}$ & $\mathrm{T}$ & $\mathrm{G}$ & \\
\hline
\end{tabular}

Observed composite haplotype identities covering both rps16I and II are listed in Table 4. Base positions 160-325 and 29-129 comprise melt domains (i) and (ii) respectively. Template differences between amplotypes give rise to discriminating melting curve $T_{\mathrm{m}}$ values in HRM. For example, $I 01$ and $I 02$ differ only in domain (i) [underlined] giving rise to divergent $T_{\mathrm{m} 1}$ peak values for these amplotypes in Fig. 2A; $I 01$ and $I 06$ also differ in domain (i) [shaded], however $I 06$ and I12 differ in both domains (i) and (ii) [shaded] giving rise to divergent $T_{\mathrm{m} 1}$ and $T_{\mathrm{m} 2}$ peak values in Fig. $2 \mathrm{~B}$. 


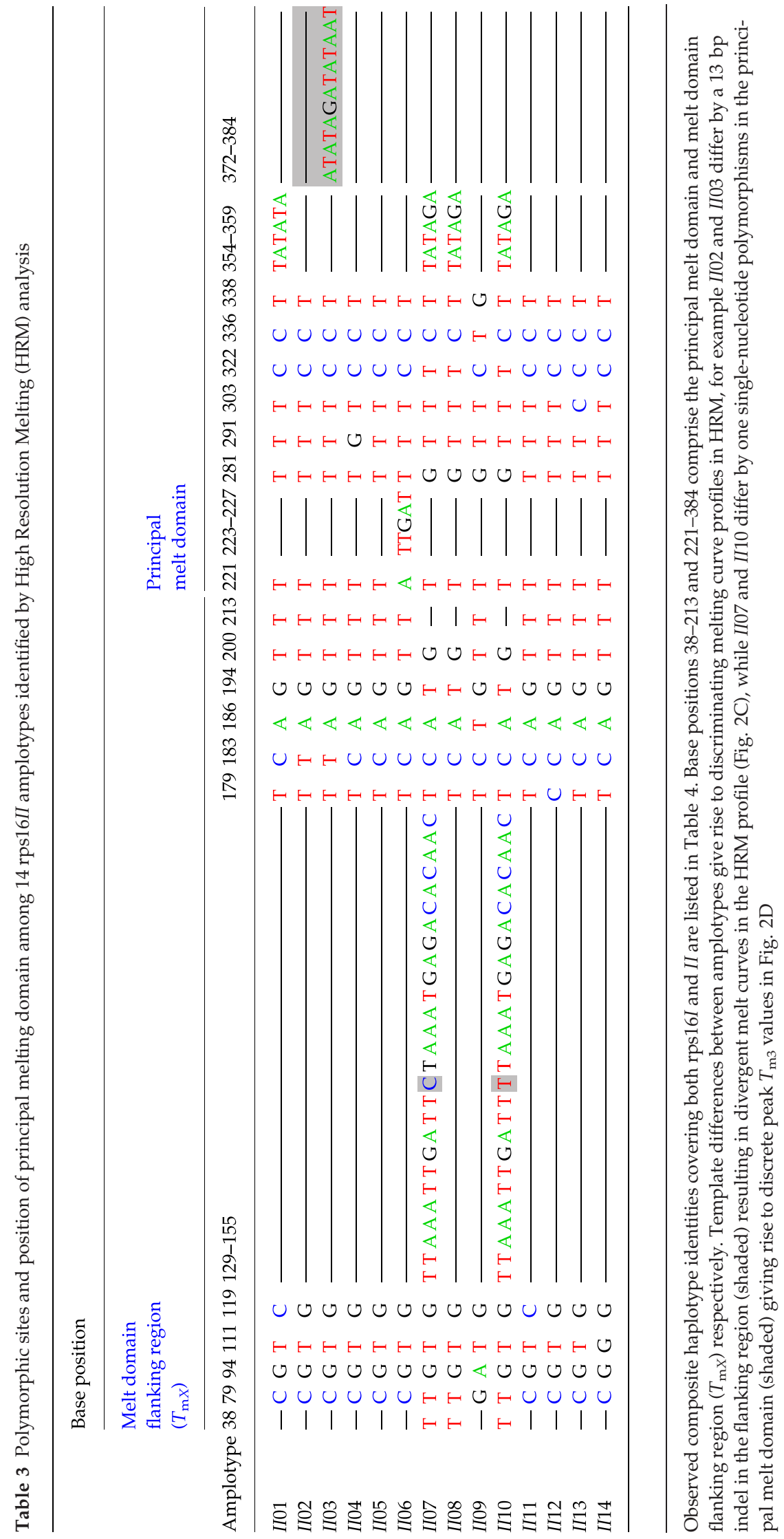


Table 4 Summary of all rps16 haplotypes identified in Arenaria ciliata (rpsC-) and Arenaria norvegica (rpsN-) using High Resolution Melting in vitro and in silico analysis of rps16I and rps16II amplicons

\begin{tabular}{|c|c|c|c|c|c|c|c|c|c|c|c|}
\hline $\begin{array}{l}\text { Composite } \\
\text { rps16 } \\
\text { haplotype }\end{array}$ & $\begin{array}{l}\text { Genbank } \\
\text { accession } \\
\text { no. }\end{array}$ & $\begin{array}{l}\text { rps16I } \\
\text { amplo } \\
\text { type }\end{array}$ & $\begin{array}{l}\text { In vitro } \\
T_{\mathrm{m} 1}\left({ }^{\circ} \mathrm{C}\right)\end{array}$ & $\begin{array}{l}\text { In silico } \\
T_{\mathrm{m} 1}\left({ }^{\circ} \mathrm{C}\right)\end{array}$ & $\begin{array}{l}\text { In vitro } \\
T_{\mathrm{m} 2}\left({ }^{\circ} \mathrm{C}\right)\end{array}$ & $\begin{array}{l}\text { In silico } \\
T_{\mathrm{m} 2}\left({ }^{\circ} \mathrm{C}\right)\end{array}$ & $\begin{array}{l}\text { rps16II } \\
\text { amplo } \\
\text { type }\end{array}$ & $\begin{array}{l}\text { In vitro } \\
T_{\mathrm{m} 3}\left({ }^{\circ} \mathrm{C}\right)\end{array}$ & $\begin{array}{l}\text { In silico } \\
T_{\mathrm{m} 3}\left({ }^{\circ} \mathrm{C}\right)\end{array}$ & $\begin{array}{l}\text { In silico } \\
T_{\mathrm{mX}}\left({ }^{\circ} \mathrm{C}\right)\end{array}$ & $\begin{array}{l}\text { Frequency of } \\
\text { haplotype by } \\
\text { populationt }\end{array}$ \\
\hline $\mathrm{rpsC01}$ & JQ945739 & $I 01$ & 76.25 & 77.7 & 79.65 & 80.6 & II01 & 76.15 & 77.7 & 75.8 & $\begin{array}{l}\text { Ir1 }(8 / 30) \text { Ir2 }(28 / 30) \\
\text { Ir3 (13/30) Ir4 (1/30) } \\
\text { Pi2 }(3 / 15)\end{array}$ \\
\hline rpsC02 & JQ945740 & $I 02$ & 75.35 & 77.3 & 79.65 & 80.6 & II02 & 75.70 & 77.4 & 76.3 & $\begin{array}{l}\text { Ir1 }(22 / 30) \text { Ir3 }(10 / 30) \\
\text { Ir4 }(29 / 30) ; A u 1(13 / 27)\end{array}$ \\
\hline $\mathrm{rpsC03}$ & JQ945741 & I02 & 75.35 & 77.3 & 79.65 & 80.6 & IIO3 & 75.70 & 77.4 & 75.7 & $\operatorname{Ir} 2(2 / 30)$ \\
\hline rpsC04 & JQ945742 & $I 03$ & 75.45 & 77.5 & 79.65 & 80.6 & IIO4 & 76.05 & 77.7 & 76.5 & $\operatorname{Ir} 3(6 / 30)$ \\
\hline $\mathrm{rpsC05}$ & JQ945743 & $I 04$ & 76.35 & 77.7 & 79.65 & 80.7 & II01 & 76.15 & 77.7 & 75.8 & $\operatorname{Ir} 3(1 / 30)$ \\
\hline rpsC06 & JQ945744 & $I 01$ & 76.25 & 77.7 & 79.65 & 80.6 & II05 & 76.15 & 77.7 & 76.3 & Py1 (7/20) Py2 (1/16) \\
\hline rpsC07 & JQ945745 & $I 01$ & 76.25 & 77.7 & 79.65 & 80.6 & II06 & 76.00 & 77.7 & 76.3 & Py1 $(2 / 20)$ \\
\hline rpsC08 & JQ945746 & $I 05$ & 75.95 & 77.5 & 79.85 & 80.8 & II05 & 76.15 & 77.7 & 76.3 & Py1 (8/20) Pi2 (2/15) \\
\hline rpsC09 & JQ945747 & $I 06$ & 76.45 & 78.1 & 79.65 & 80.6 & II07 & 75.80 & 77.3 & 76.1 & $\begin{array}{l}\text { It1 }(26 / 26) \text { It2 }(1 / 1) \\
\text { It3 }(3 / 4) \text { Au2 }(8 / 25)\end{array}$ \\
\hline rpsC10 & JQ945748 & $I 07$ & 76.40 & 78.1 & 79.95 & 80.9 & $I I 08$ & 75.60 & 77.2 & 76.1 & It3 $(1 / 4)$ \\
\hline $\mathrm{rpsC} 11$ & JQ945749 & $I 08$ & 76.50 & 78.0 & 79.10 & 80.3 & II09 & 75.70 & 77.4 & 76.3 & Fr1 $(2 / 5)$ \\
\hline rpsC12 & JQ945750 & $I 09$ & 75.95 & 77.5 & 79.65 & 80.6 & II05 & 76.15 & 77.7 & 76.3 & Py1 (3/20) Py2 (1/16) \\
\hline rpsC13 & JQ945751 & $I 06$ & 76.45 & 78.1 & 79.65 & 80.6 & $I I 10$ & 75.60 & 77.0 & 76.1 & Fr1 $(3 / 5)$ \\
\hline $\mathrm{rpsC} 14$ & JQ945752 & $I 01$ & 76.25 & 77.7 & 79.65 & 80.6 & III1 & 76.15 & 77.7 & 76.3 & $\begin{array}{l}\text { Pi1 (16/18) Py2 (14/16) } \\
\text { Au2 (4/25) }\end{array}$ \\
\hline rpsC15 & JQ945753 & $I 10$ & 75.60 & 77.5 & 79.00 & 80.0 & III12 & 76.55 & 77.9 & 76.3 & $\begin{array}{l}\text { Pi1 (2/18) Pi2 (9/15) } \\
\text { Pi3 (19/19) }\end{array}$ \\
\hline rpsC16 & JQ945754 & $I 11$ & 76.35 & 77.8 & 79.65 & 80.6 & II07 & 75.80 & 77.3 & 76.1 & Pi2 (1/15) \\
\hline rpsC17 & JQ945755 & $I 01$ & 76.25 & 77.7 & 79.65 & 80.6 & $I I 13$ & 76.10 & 77.7 & 76.6 & Au1 (14/27) \\
\hline rpsC18 & JQ945756 & $I 12$ & 75.85 & 77.9 & 79.10 & 80.3 & II09 & 75.70 & 77.4 & 76.3 & Au2 (13/25) \\
\hline rpsN01 & JQ945757 & $I 13$ & 76.10 & 77.4 & 79.65 & 80.6 & II05 & 76.15 & 77.7 & 76.3 & $\begin{array}{l}\text { NB }(30 / 30) \text { NE }(20 / 20) \\
\text { NIc }(2 / 2) \text { NIn }(30 / 30) \\
\text { NR }(11 / 29) \text { NS }(29 / 29)\end{array}$ \\
\hline rpsN02 & JQ945758 & $I 14$ & 75.05 & 77.0 & 79.65 & 80.6 & $I I 14$ & 76.50 & 77.9 & 76.3 & NR (18/29) \\
\hline
\end{tabular}

tKey to Population identity. A. ciliata: Ir1, Ir2, Ir3, Ir4, Ben Bulben Plateau, NW Ireland; Pi1, Pi2, Pi3, Picos de Europa, Spain; Py1, Py2, Valle de Benasque, Pyrenees, Spain; It1, It2, It3, Piemonte, Alps, Italy; Fr1, Col D’ Agnel, Alps, France; Au1, Au2, Steiermark, Alps, Austria. A. norvegica: NB, Burren, Ireland; NE, Yorkshire, England; Nic, Eldgja gorge, Iceland; Nin, Inchnadamph, Scotland; NR, Isle of Rum, Scotland; NS, Shetland Islands, Scotland.

\section{Rps16II data}

Amplicon melting curves for rps16II showed lower resolution than for rps16I. Three different amplotypes, II01, II05 and II11 that differ by one G/C substitution and/or a $6 \mathrm{bp}$ indel have the same $T_{\mathrm{m} 3}$ at $76.15^{\circ} \mathrm{C}$. II 01 can be distinguished from both of the latter at $T_{\mathrm{mX}}$, however II05 and II11 (which co-occur in population Py2 as part of composite haplotypes C06 and C14, respectively, Fig. 3) cannot be distinguished from one another based on the rps16II melting curve. Amplotype II09 differs markedly (minimum seven point mutations) from both $\mathrm{II02}$ and II03, but has the same $T_{\mathrm{m} 3}$ value as both $\left(75.70{ }^{\circ} \mathrm{C}\right)$. The latter two amplotypes differ by a single indel of $13 \mathrm{bp}$, which is associated with divergent $T_{\mathrm{mX}}$ shoulder curves between the two (Fig. 2D), however none of these rps16II amplotypes co-occur within a single population (Fig. 3).
The averaged $T_{\mathrm{m} 3}$ values of two geographically distant rps16II amplotypes II12 (A. ciliata Spain) and II14 (A. norvegica Scotland) varied by only $0.05{ }^{\circ} \mathrm{C}$, which is below the limit of HRM resolution, however these amplotypes were successfully identified by following the protocol to sequence all putative amplotypes in each population.

\section{In vitro sensitivity to SNPS}

Among all possible pairwise comparisons between amplotypes, single nucleotide polymorphisms constituted the sole difference between templates in 12 cases, 11 of which were identifiable by HRM (e.g. II07 and II10, Fig. 2C). In eight cases the pairwise $\Delta T_{\mathrm{m}}$ was $>0.2{ }^{\circ} \mathrm{C}$. In two cases discrimination at $<0.2{ }^{\circ} \mathrm{C}$ was achieved using the $T_{\mathrm{mX}}$ shoulder in rps16II, and in one case a shift of $<0.2{ }^{\circ} \mathrm{C}$ was evident in $T_{\mathrm{m} 1}$ in rps16I. Only one case, a class III transversion SNP in 


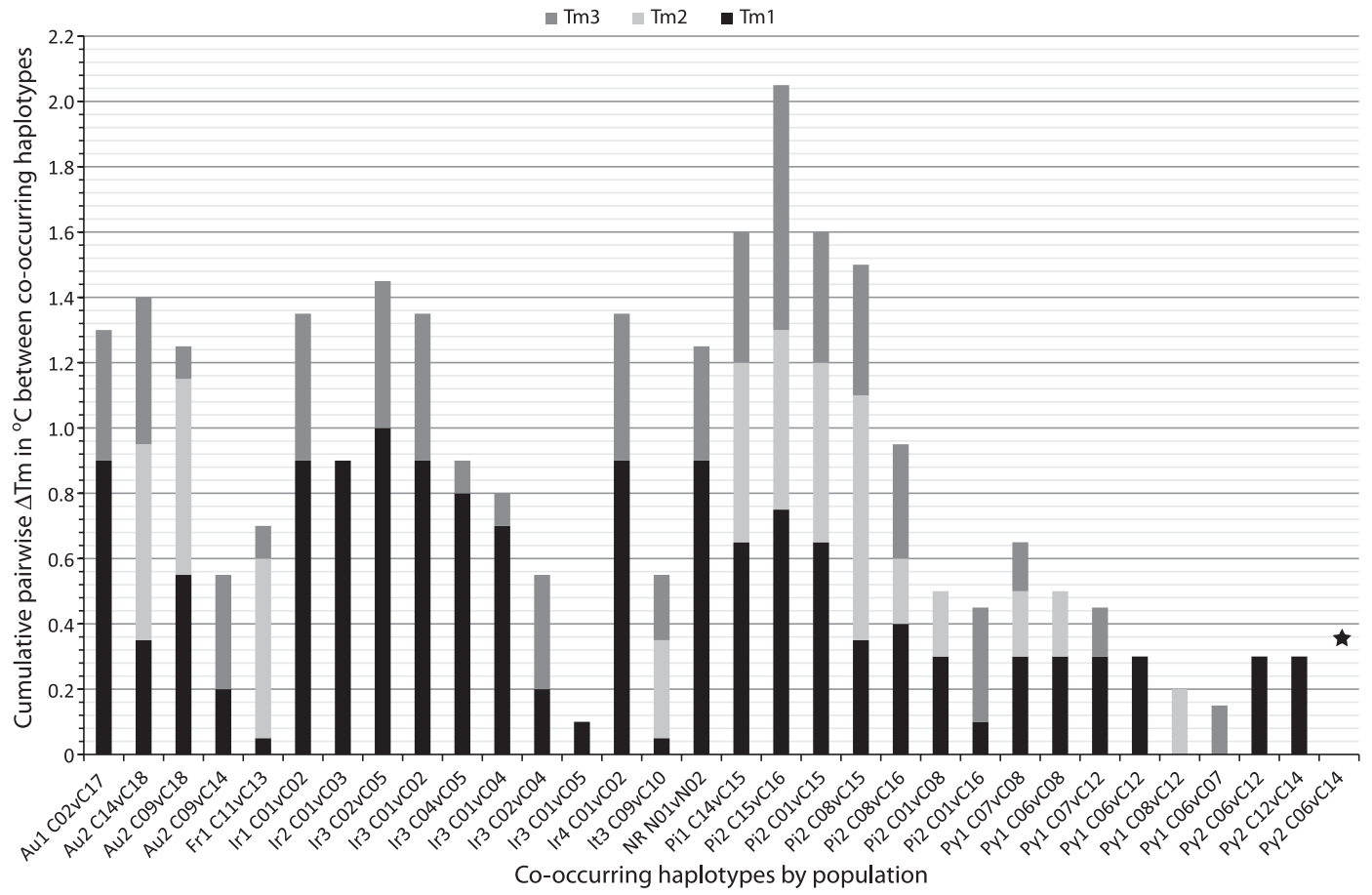

Fig. 3 Observed total pairwise $\Delta T_{\mathrm{m}}$ between haplotypes that co-occur in the same sampled population based on combined differences in $T_{\mathrm{m} 1}, T_{\mathrm{m} 2}$ and $T_{\mathrm{m} 3}$ values. Only Py2 CO6 vs. C14 failed to yield any discrete $\Delta T_{\mathrm{m}}$ value between the haplotypes, indicated by a star.

rps16II (G-C), was not discernable via initial HRM analysis. Overall class I transition SNPs (G-T or A-C) were most easily detected (five of six $\Delta T_{\mathrm{m}}>0.2^{\circ} \mathrm{C}$ ), followed by class II transversion SNPs (A-C or G-T) (three of five $\Delta T_{\mathrm{m}}>0.2^{\circ} \mathrm{C}$ ). No class IV transversion SNPs were recorded.

No differences were discernable in the melting curve profile between II05 and III1, and II05 was initially detected by sequencing at least 2 samples that showed the putative II11 amplotype curve for rps16II in population Py2. Sequence analysis of all 14 putative II11 amplotypes in Py2 confirmed just one individual of $I I 05$.

Sensitivity to differences between co-occurring haplotypes

Among co-occurring haplotypes within the sampled populations, only three of 32 inter haplotype comparisons failed to yield at least one $\Delta T_{\mathrm{m}}$ value that exceeded the nominal discriminating threshold of $0.2{ }^{\circ} \mathrm{C}$ for $T_{\mathrm{m} 1}, T_{\mathrm{m} 2}$ or $T_{\mathrm{m} 3}$ (Fig. 3). Two of these inter haplotype comparisons were reliably distinct below the $0.2^{\circ} \mathrm{C}$ threshold; C06/C07 in Py1 $\left(\Delta T_{\mathrm{m} 3}\right.$ 0.15) and C01/C05 in Ir3 $\left(\Delta T_{\mathrm{m} 1}\right.$ $0.1)$. Only one inter haplotype comparison, C06/C14 in Py2 $\left(\Delta T_{\mathrm{m} 1}, 2,3=0\right)$, as discussed above, was not distinguishable by HRM. The combined array of $T_{\mathrm{m} 1}, T_{\mathrm{m} 2}, T_{\mathrm{m} 3}$ and $T_{\mathrm{mX}}$ values thus provided a unique identifier for 18 of 20 composite haplotypes identified in the analysis and validated by sequencing (Table 4 , Fig. 3 ). While the overall sequence composition for each of these composite haplotypes was unique, seventeen of the twenty shared at least one rps16I or II sequence identity with another haplotype, only three composite haplotypes included entirely unique sequences in both regions (C04, C10 and C15).

\section{Correlation between $\Delta \mathrm{T}_{m}$ and genetic distance}

A Mantel test analysis of compounded $T_{\mathrm{m} 1}, T_{\mathrm{m} 2}$ and $T_{\mathrm{m} 3}$ differences between haplotypes and the corresponding pairwise inter haplotype Tajima-Nei genetic distance $D$ showed that the two measures of difference were significantly correlated at $P<0.05$ (Table 5), however when analysed separately no significant correlation was evident for either $T_{\mathrm{m} 1}, T_{\mathrm{m} 2}$ vs. $D$ or for $T_{\mathrm{m} 3}$ vs. $D$.

In silico simulation (i): evaluating the utility of in silico HRM modelling as a support for in vitro HRM analysis

In silico simulation of rps16I melting using uMelt ${ }^{\mathrm{SM}}$ generates two clear $T_{\mathrm{m}}$ peaks, as for the in vitro results, while in silico rps16II generates two peaks, one clear peak corresponding to $T_{\mathrm{m} 3}$, and a second less-pronounced peak corresponding to the shoulder $T_{\mathrm{mX}}$ region in the in vitro melting analysis. The corresponding values of $T_{\mathrm{m} 1}, 2,3$ 
Table 5 Results of Mantel correlation tests between observed in vitro inter haplotype $\Delta T_{\mathrm{m}}$, modelled in silico inter haplotype $\Delta T_{\mathrm{m}}$, and calculated inter haplotype genetic distance (Tajima-Nei's D)

\begin{tabular}{|c|c|c|c|c|}
\hline & & & $\rho$ & $P$ \\
\hline \multirow{3}{*}{$\begin{array}{l}\text { Inter amplotype } \\
\Delta T_{\mathrm{m}} \text { in vitro vs. in } \\
\text { silico }\end{array}$} & $\Delta T_{\mathrm{m} 1}$ in vitro vs. $\Delta T_{\mathrm{m} 1}$ in silico & & 0.6247 & $0.0001^{* * *}$ \\
\hline & $\Delta T_{\mathrm{m} 2}$ in vitro vs. $\Delta T_{\mathrm{m} 2}$ in silico & & 0.9257 & $0.0001^{* * *}$ \\
\hline & $\Delta T_{\mathrm{m} 3}$ in vitro vs. $\Delta T_{\mathrm{m} 3}$ in silico & & 0.7964 & $0.0001^{* * *}$ \\
\hline \multirow{6}{*}{$\begin{array}{l}\text { Inter haplotype } \\
\Delta T_{\mathrm{m}} \text { vs. Tajima-Nei } \\
\text { genetic distance } D \\
\text { between haplotypes }\end{array}$} & $\left|\Delta T_{\mathrm{m} 1}+\Delta T_{\mathrm{m} 2}\right|$ vs. $D_{\mathrm{rps} 16 I}$ & In vitro & 0.2168 & 0.0858 \\
\hline & & In silico & 0.4468 & $0.0021^{* *}$ \\
\hline & $\Delta T_{\mathrm{m} 3}$ vs. $D_{\mathrm{rps} 16 I I}$ & In vitro & 0.2118 & 0.0886 \\
\hline & & In silico & 0.5088 & $0.0015^{* *}$ \\
\hline & $\left|\Delta T_{\mathrm{m} 1}+\Delta T_{\mathrm{m} 2}+\Delta T_{\mathrm{m} 3}\right|$ vs. $D_{\mathrm{rps} 16}$ & In vitro & 0.3593 & $0.0122^{*}$ \\
\hline & $\begin{array}{l}\left|\Delta T_{\mathrm{m} 1}+\Delta T_{\mathrm{m} 2}+\Delta T_{\mathrm{m} 3}+\Delta T_{\mathrm{m} X}\right| \\
\text { vs. } D_{\mathrm{rps} 16}\end{array}$ & In silico & 0.4189 & $0.0012^{* *}$ \\
\hline
\end{tabular}

*Correlation is significant at $P<0.05$.

${ }^{* *}$ Correlation is significant at $P<0.01$.

***Correlation is significant at $P<0.001$.

and $T_{\mathrm{mX}}$ (for the shoulder with rps16II) from in silico simulation are listed in Table 4.

A linear regression was performed to evaluate the consistency between the in vitro and in silico $T_{\mathrm{m} 1}, T_{\mathrm{m} 2}$ and $T_{\mathrm{m} 3}$ values for each haplotype (estimated $R^{2}=0.9902$, Fig. S2, Supporting information). The similarity between in vitro and in silico pairwise inter haplotype $\Delta T_{\mathrm{m}}$ matrices was evaluated by Mantel test for $T_{\mathrm{m} 1}(r=0.6247$, $P=0.0001), \quad T_{\mathrm{m} 2} \quad(r=0.9257, \quad P=0.0001) \quad$ and $\quad T_{\mathrm{m} 3}$ ( $r=0.7964, P=0.0001)$, with detailed results shown in Table 5. Both regression and Mantel tests suggest that in vitro and in silico $T_{\mathrm{m}}$ values are significantly correlated.

All the amplotypes that are distinguishable by in silico HRM analysis (varying by $\geq 0.1{ }^{\circ} \mathrm{C}$ ) can also be distinguished by in vitro analysis, and amplotypes that share the same in silico $T_{\mathrm{m}}$ values also share the same in vitro $T_{\mathrm{m}}$ values, e.g. II05 and II11 share in silico $T_{\mathrm{m} 3}=77.7^{\circ} \mathrm{C}$ and in vitro $T_{\mathrm{m} 3}=76.15^{\circ} \mathrm{C}$. However, one exception emerged between amplotypes II05 and II06 which share the same in silico $T_{\mathrm{m} 3}$ value $\left(77.7^{\circ} \mathrm{C}\right)$ but have distinct $T_{\mathrm{m} 3}$ values in vitro (76.15 and $76.00{ }^{\circ} \mathrm{C}$, respectively).

In silico simulation (ii): sensitivity of HRM to singlesubstitution mutations between haplotypes -in silico evaluation of single substitutions in a wild-type template

Within the 352 bp region of rps16I, class I (transition A to G or $\mathrm{C}$ to $\mathrm{T}$ ) and class II (transversion $\mathrm{A}-\mathrm{C}$ or $\mathrm{G}-\mathrm{T}$ ) mutations were generated on all the nucleotide sites between site 22 and 327 (i.e. 306 mutant amplotypes obtained for each of class I and II mutations), while class III (transversion C-G) and IV (transversion A-T) mutations were generated on all possible sites within the same region (95 class III mutants by mutation on C and G sites and 211 class IV mutants on A and T sites) (Fig. S3, Supporting information).
In total 303 out of the 306 class I mutant amplotypes were given $T_{\mathrm{m} 1}$ or $T_{\mathrm{m} 2}$ values more than $0.1{ }^{\circ} \mathrm{C}$ different from the wild type $\left(T_{\mathrm{m} 1}=77.7{ }^{\circ} \mathrm{C}\right.$ and $\left.T_{\mathrm{m} 2}=80.6{ }^{\circ} \mathrm{C}\right)$, indicating a detection rate of $303 / 306=99.02 \%$ for class I single mutations (Fig. S3, Supporting information). In the same way, the detection rate for class II single mutation is also $303 / 306=99.02 \%$, while it is $46 / 95=48.42 \%$ for class III and $81 / 211=38.39 \%$ for class IV single mutations, respectively.

Within the $306 \mathrm{bp}$ detectable region, there are in total 918 possible single substitution mutations, of which there are 95 class III, 211 class IV and 612 class I and II mutations. The estimated overall missed SNP detection rate for the rps16I A. ciliata wild-type amplicon is thus estimated at $20.15 \%$. This indicates that if there is a single substitution mutation in the target region between haplotypes, the possibility we cannot detect it by HRM analysis is around $20 \%$.

\section{Performance of in silico RFLP}

The in silico RFLP undertaken on the 20 distinct haplotype sequences obtained through HRM showed that 12 putative haplotypes were distinguishable by this method. Only seven of these corresponded exactly to one of the HRM-identified haplotypes (Table S2, Supporting information), the other five putative haplotypes corresponded to either two or three different haplotypes identified through HRM. In terms of discriminating haplotype identity the overall resolution of the in silico RFLP is 35\% $(7 / 20)$ in comparison to the $90 \%(18 / 20)$ for HRM.

\section{Discussion}

The protocol presented here was designed to evaluate whether HRM can provide a practical and effective 
method for haplotype identification. The size of the target amplicons was determined based on joint consideration of DNA coverage, sensitivity and cost, an approach that was not guaranteed a priori to provide optimal performance. The threshold of $T_{\mathrm{m}}$ difference for amplotype discrimination was also questionable at $0.2{ }^{\circ} \mathrm{C}$ before our study, so we applied posterior DNA sequencing after HRM analysis to evaluate the efficacy of this threshold. The method as tested has generated highly detailed haplotype identity and frequency data for Arenaria ciliata and Arenaria norvegica. Working with the two targeted amplicons rps16 I and II, HRM analysis revealed all but one of the haplotypes that were finally confirmed by DNA sequencing, allowing discrete haplotype identification in 379 of 380 possible pairwise haplotype comparisons, including 31 of 32 observed co-occurrences of haplotypes within single populations (Fig. 3). Initially there was concern that the chosen amplicons (350-400 bp) might be too long compared to established HRM norms; however, the accuracy of the analysis was sustained over these amplicon size intervals, in particular due to the presence of multiple melting domains in the double-stranded amplified DNA.

From both in vitro and in silico analyses, the melting peak corresponding to $T_{\mathrm{m} 1}$ in melting domain (i) of the rps16I amplicon was the most discriminative indicator (Fig. 2A,B). The average inter amplotype $\Delta T_{\mathrm{m} 1}$ values were $0.46{ }^{\circ} \mathrm{C}$ in vitro and $0.31{ }^{\circ} \mathrm{C}$ in silico, compared to $0.24 / 0.20{ }^{\circ} \mathrm{C}$ (for $\Delta T_{\mathrm{m} 2}$ ), and $0.31 / 0.26{ }^{\circ} \mathrm{C}$ (for $\Delta T_{\mathrm{m} 3}$ ). While amplotypes of rps16I were identified distinctly with $T_{\mathrm{m} 1}$ and $T_{\mathrm{m} 2}$, amplotypes of rps16II were not so easily distinguished with $T_{\mathrm{m} 3}$ alone, and this may be related to the slightly larger amplicon size compared to rps16I. However the $T_{\mathrm{mX}}$ shoulder that flanks the principal melting domain $T_{\mathrm{m} 3}$ did discriminate between a number of otherwise similar rps16II amplotypes, e.g. between $I I 02$ and II03 (Fig. 2B). While the $T_{\mathrm{mX}}$ region lacked a discernable peak in our in vitro HRM profiles and it was not possible to assign precise $T_{\mathrm{mX}}$ values to amplotypes, discrete $T_{\mathrm{mX}}$ curve patterns were evident between many amplotypes.

In only three cases did haplotypes that co-occurred within a single population have no pairwise $\Delta T_{\mathrm{m}}$ value of $\geq 0.2{ }^{\circ} \mathrm{C}$ at any of $T_{\mathrm{m} 1}, T_{\mathrm{m} 2}$ or $T_{\mathrm{m} 3}$ (Fig. 3). In two of these cases a smaller but consistent $\Delta T_{\mathrm{m}}$ of $0.10-0.15^{\circ} \mathrm{C}$ was evident, and once sequence content and observed $T_{\mathrm{m}}$ variation were confirmed, discrimination of these haplotype samples by HRM was possible. In one single case all $\Delta T_{\mathrm{m}}$ values between a haplotype pair were $0{ }^{\circ} \mathrm{C},(\mathrm{C} 06$ and $\mathrm{C} 14$ in population Py2 deviated by a single class III $\mathrm{C} / \mathrm{G}$ mutation in rps16II), which is the only case where HRM analysis failed to distinguish between two haplotypes in our study.

Sensitivity of the analysis may have been impacted by the quality of the DNA template. This work utilized a
DNA sample set that had been extracted using a modified CTAB method, which doesn't guarantee a uniform chemical composition for the extracted DNA. The potentially lower quality of our DNA template may thus have had an impact on subsequent melting analysis, generating system errors between $T_{\mathrm{m}}$ readings of different batches of HRM assays. However despite these errors within in vitro analysis, the Mantel-test correlation with modelled in silico $\Delta T_{\mathrm{m}}$ values for the equivalent amplotype templates was significant at $P<0.001$, indicating the obtained in vitro $\Delta T_{\mathrm{m}}$ values do reflect DNA variation among the haplotypes as predicted by in silico simulation.

Also it is clear that where two amplotypes can be distinguished by in silico simulation (by $0.1{ }^{\circ} \mathrm{C}$ ) using uMelt $^{\mathrm{SM}}$, they can also be distinguished by HRM analysis on the LightCycler 480 system. Occasionally in vitro HRM analysis produces even higher resolution than in silico simulation, e.g. rps16I amplotypes $I 09$ and $I 10$ shared the same in silico $T_{\mathrm{m} 1}=77.5{ }^{\circ} \mathrm{C}$ but have different in vitro $T_{\mathrm{m} 1}$ values ( $0.35{ }^{\circ} \mathrm{C}$ difference). While estimates of precise ${ }^{\circ} \mathrm{C}$ values of $T_{\mathrm{m}}$ peaks differ between the two methods as we have applied them, the underlying pattern of inter haplotype $\Delta T_{\mathrm{m}}$ identification is equivalent between the two (mantel test of correlation between pairwise $\Delta T_{\mathrm{m}}$ matrices is significant at $P<0.001$ Table 5). Overall this data affirms both that in silico modelling is a valid support for in vitro HRM work, and that the model parameters applied in $\mathrm{uMelt}^{\mathrm{SM}}$ generate slightly conservative estimates of HRM curve difference between amplotypes.

As mentioned above, the limited resolution of HRM means that it is not an equivalent to template sequencing, however a more general correlation between inter haplotype $\Delta T_{\mathrm{m}}$ values and inter haplotype genetic distance is a possibility. Mantel tests on the in vitro and in silico data here (Table 5) showed a significant positive correlation between the compounded differences in $\Delta T_{\mathrm{m} 1}$, two and three between haplotypes and the corresponding pairwise Tajima-Nei genetic distance $D$ between haplotypes. Thus while certain haplotype pairs in the study with large pairwise $D$ values did have very similar meltingcurve profiles, these correlation tests on our data support the case that in general a greater $\Delta T_{\mathrm{m}}$ value between haplotypes indicates a greater level of evolutionary divergence.

In silico modelling of HRM sensitivity to different SNP mutation classes on the wild-type rps16I amplicon confirmed that transition SNPs (class I mutations) and class II transversion SNPs are easier to detect than Class III and IV transversions (Liew et al. 2004). Our in vitro results show the former classes can be detected by HRM analysis when occurring in an amplicon up to $360 \mathrm{bp}$ (rps16I, one case of class II SNP) or 390 bp (rps16II, one case of class I $\mathrm{SNP}$ ) at or above the $0.2{ }^{\circ} \mathrm{C}$ threshold we selected for identifying between-amplicon deviation. In silico HRM model- 
ling estimated the likely incidence of silent SNPs in rps16I to be $51.58 \%$ and $61.61 \%$ for class III and IV mutations respectively, compared to just $0.98 \%$ for Class I and II mutations. In our haplotype dataset four Class III and two Class IV SNPs were observed, however only in one case (a Class III G/C mutation between II05 and II11) did this mutation constitute the sole difference between composite haplotypes-and this was the only instance where HRM failed to distinguish between haplotypes.

By assuming the likelihood of some silent mutations in the analysis, our protocol required that two or three individual representatives from each putative amplotype were sequenced from each population. In total over 80 sequences were obtained, and in only one case was an amplotype sequence returned that was not discernable by HRM analysis. This contrasts with the results of the in silico RFLP analysis (Table S2, Supporting information), where only $35 \%$ of the recorded haplotypes could be detected uniquely. HRM sensitivity to silent SNPs in larger amplicons can be improved by reducing amplicon size at the specific SNP locus using new internal primers. In addition, it is common in diagnostic HRM applications to identify the presence of specific SNPs by categorizing nuclear genotypic (dual template) samples as either homozygous or heterozygous for the SNP in question (Wittwer et al. 2003). While we have not evaluated this approach for discriminating between dual templates in the current work, pooling amplotype samples may provide additional sensitivity for otherwise silent SNPs among samples that share the same HRM curve. However the only assurance of total haplotype coverage is to sequence every sample (Liew et al. 2004; Wittwer 2009).

Compared to the alternative approach of sequencing every single accession (446) to generate a total count of haplotype frequency data across the population samples, the resources required for the HRM method were significantly reduced. Although sequence analysis was not exhaustive, we are confident that the method effectively identified haplotypes in the sampled populations. In particular, while the low haplotype diversity of $A$. norvegica suggests a characteristic post pleistocene south-to-north expansion similar to many European plant species (Taberlet et al. 1998), A. ciliata appears to be much more diverse, and the multiple endemic haplotypes identified in populations in Ireland are suggestive of an origin that predates the last glacial maximum (LGM) c. 20000 years ВР (Table 4, Fig. S1, Supporting information), akin to other patterns recently emerging from analysis of the arctic-alpine flora (Schneeweiss \& Schonswetter 2011). This may be a significant finding and offers tentative phylogeographic support for a postulated nunatak on the Ben Bulben plateau in Northwest Ireland throughout the LGM (Synge \& Wright 1969). A more detailed phylogeo- graphic analysis of this and other data, including taxonomic inferences, will be presented in an upcoming paper (In prep).

Based on the results we have detailed, HRM haplotype analysis is suitable for a wide range of phylogeographic studies where polymorphism is evident in commonly used $400+$ bp spacer regions in chloroplast and mitochondrial DNA (e.g. Shaw et al. 2005). The limitations of the method are similar to direct sequencing in that individual loci may not contain informative polymorphisms below the species level. However, in any studied organism where discrete organelle DNA differentiation is evident between population sub-groups, or where cryptic speciation has occurred, HRM has the capacity to greatly increase the scope and sensitivity of haplotype analysis.

These advantages may be relevant for future work both on regional meta-populations with significant intermixing of diverse biogeographic stock (e.g. European tree species., Petit et al. 2003), and in species populations with disjunct distributions, (e.g. Arenaria and Sagina spp in the Holarctic, Westergaard et al. 2011). Population sample groups with similar levels of haplotype diversity to what we have recorded for $A$. ciliata are already common in the literature; recent examples include the Mediterranean tree frog Hyla sarda (37 mitochondrial cyt $b$ gene haplotypes, Bisconti et al. 2011) and the Mexican mountain shrub Palicourea padifolia (14 chloroplast rpl32-trnL spacer haplotypes, Gutiérrez-Rodríguez et al. 2011). Phylogeographic data compiled by Petit et al. (2005) indicated an average of 12.3 haplotypes per species across 183 angiosperm and gymnosperm taxa, with 47 displaying more than 15 discrete chloroplast or mitochondrial haplotypes across their distribution. Equally, many newly detected cryptic species have also come to light via organelle haplotype variation (e.g. the Neotropical tree Cedrela fissilis, Garcia et al. 2011; and the north Atlantic Littorina saxatilis, Doellman et al. 2011).

Bearing in mind the sensitivity limitations and errorminimization requirements documented in this current work, all of the above studies are amenable to HRM haplotype analysis. There is considerable scope for improvement in this technique, for example in the optimization of amplicon design and selection protocols, and evaluation of (potentially heterozygous) large nuclear loci such as ITS. However, for any organism where comparative sequence data has already been generated, in silico HRM analysis can be carried out to evaluate the utility of deploying the method alongside existing protocols for direct sequencing or PCR-RFLP. With wider availability of real-time PCR equipment, and the superior sensitivity of HRM to mutational differences compared to PCRRFLP, the method likely represents an untapped resource in phylogeographic analysis. 


\section{Acknowledgements}

Xiaodong Dang is funded by a John and Pat Hume Scholarship from the National University of Ireland Maynooth. This project and the graduate scholarship for Emma Howard-Williams were funded by Science Foundation Ireland (Grant No.: SFI/08/RFP/EOB1545). Quantitative PCR instrumentation was funded by Science Foundation Ireland (Grant No.: SFI/07/RFP/GEN/F571/ECO7). Adreas Tribsch (Salzburg), Kevin Walker (BSBI), Pablo Vargas (Madrid) and Patrick Kuss (Bern) assisted with field collections.

\section{References}

Angiosperm Phylogeny Group III (2009) An update of the Angiosperm Phylogeny Group classification for the orders and families of flowering plants: APG III. Botanical Journal of the Linnean Society, 161, 105-121.

Bettin O, Cornejo C, Edwards PJ, Holderegger R (2007) Phylogeography of the high alpine plant Senecio halleri (Asteraceae) in the European Alps: in situ glacial survival with postglacial stepwise dispersal into peripheral areas. Molecular Ecology, 16, 2517-2524.

Bisconti R, Canestrelli D, Colangelo P, Nascetti G (2011) Multiple lines of evidence for demographic and range expansion of a temperate species (Hyla sarda) during the last glaciation. Molecular Ecology, 20, 5313-5327.

Doellman MM, Trussell GC, Grahame JW, Vollmer SV (2011) Phylogeographic analysis reveals a deep lineage split within North Atlantic Littorina saxatilis. Proceedings of the Royal Society of London. Series B, Containing Papers of a Biological Character. Royal Society (Great Britain), 278, 3175-3183.

Doyle JJ, Doyle JL (1987) A rapid DNA isolation procedure for small quantities of fresh leaf tissue. Phytochemical Bulletin, 19, 11-15.

Dwight Z, Palais R, Wittwer CT (2011) UMELT: prediction of high-resolution melting curves and dynamic melting profiles of PCR products in a rich web application. Bioinformatics, 27, 1019-1020.

Garcia MG, Silva RS, Carniello MA et al. (2011) Molecular evidence of cryptic speciation, historical range expansion, and recent intraspecific hybridization in the Neotropical seasonal forest tree Cedrela fissilis (Meliaceae). Molecular Phylogenetics and Evolution, 61, 639-649.

Gutiérrez-Rodríguez C, Ornelas JF, Rodríguez-Gómez F (2011) Chloroplast DNA phylogeography of a distylous shrub (Palicourea padifolia, Rubiaceae) reveals past fragmentation and demographic expansion in Mexican cloud forests. Molecular Phylogenetics and Evolution, 61, 603615.

Hall TA (1999) BioEdit:a user-friendly biological sequence alignment editor and analysis program for Windows 95/98/NT. Nucleic Acids Symposium Series, 41, 95-98.

Huguet JM, Bizarro CV, Forns N et al. (2010) Single-molecule derivation of salt dependent base-pair free energies in DNA. Proceedings of the National Academy of Sciences of the United States of America, 107, 15431-15436.

Jalas J, Suominen J (1983) Atlas Florae Europaeae: Distribution of Vascular Plants in Europe, Volume 6: Caryophyllaceae (Alsinoideae and Paronychioideae). Committee for Mapping the Flora of Europe, Helsinki.

Liew M, Pryor R, Palais R et al. (2004) Genotyping of single-nucleotide polymorphisms by high-resolution melting of small amplicons. Clinical Chemistry, 50, 1156-1164.

Mader E, Lohwasser U, Börner A, Novak J (2010) Population structures of genebank accessions of Salvia officinalis L. (Lamiaceae) revealed by high resolution melting analysis. Biochemical Systematics and Ecology, 38, 178-186.

Mantel N (1967) The detection of disease clustering and a generalized regression approach. Cancer Research, 27, 209-220.

Petit RJ, Aguinagalde I, de Beaulieu J-L et al. (2003) Glacial refugia: hotspots but not melting pots of genetic diversity. Science, 300, 1563-1565.

Petit RJ, Duminil J, Fineschi S et al. (2005) Comparative organization of chloroplast, mitochondrial and nuclear diversity in plant populations. Molecular Mcology, 14, 689-701.
R Development Core Team (2011) R: A Language and Environment for Statistical Computing. R Foundation for Statistical Computing, Vienna.

Reed GH, Wittwer CT (2004) Sensitivity and specificity of single-nucleotide polymorphism scanning by high-resolution melting analysis. Clinical Chemistry, 50, 1748-1754.

Ririe KM, Rasmussen RP, Wittwer CT (1997) Product differentiation by analysis of DNA melting curves during the polymerase chain reaction. Analytical Biochemistry, 245, 154-160.

Schneeweiss GM, Schonswetter P. (2011) A re-appraisal of nunatak survival in arctic-alpine phylogeography. Molecular Ecology, 20, 190-192.

Shaw J, Lickey EB, Beck JT et al. (2005) The tortoise and the hare II: relative utility of 21 noncoding chloroplast DNA sequences for phylogenetic analysis. American Journal of Botany, 92, 142-166.

Shaw J, Lickey EB, Schilling EE, Small RL (2007) Comparison of whole chloroplast genome sequences to choose noncoding regions for phylogenetic studies in angiosperms: the tortoise and the hare III. American Journal of Botany, 94, 275-288.

Smith BL, Lu C-P, Alvarado Bremer JR (2010) High-resolution melting analysis (HRMA): a highly sensitive inexpensive genotyping alternative for population studies. Molecular Ecology Resources, 10, 193-196.

Studer B, Jensen LB, Fiil A, Asp T (2009) "Blind" mapping of genic DNA sequence polymorphisms in Lolium perenne L. by high resolution melting curve analysis. Molecular Breeding, 24, 191-199.

Synge FM, Wright HEJ (1969) The Würm ice limit in the West of Ireland. In: Quaternary Geology and Climate (ed. Wright HE), pp. 89-92. National Academy of Sciences, Washington, District of Columbia.

Taberlet P, Fumagalli L, Wust-Saucy A-G, Cosson J-F (1998) Comparative phylogeography and postglacial colonization routes in Europe. Molecular Ecology, 7, 453-464.

Tajima F, Nei M (1984) Estimation of evolutionary distance between nucleotide sequences. Molecular Biology and Evolution, 1, 269-285.

Teacher AGF, Garner TWJ, Nichols RA (2009) European phylogeography of the common frog (Rana temporaria): routes of postglacial colonization into the British Isles, and evidence for an Irish glacial refugium. Heredity, 102, 490-496.

Thioulouse J, Chessel D, Dolédec S, Olivier JM (1997) ADE-4: a multivariate analysis and graphical display software. Statistics and Computing, 7, 75-83.

Tutin TG, Burges NA, Chater AO et al. (1993) Flora Europaea, Volume 1: Psilotaceae to Platanaceae. Cambridge University Press, Cambridge.

Vincze T, Posfai J, Roberts RJ (2003) NEBcutter: a program to cleave DNA with restriction enzymes. Nucleic Acids Research, 31, 3688-3691.

Vossen RHAM, Aten E, Roos A, den Dunnen JT (2009) High-resolution melting analysis (HRMA): more than just sequence variant screening. Human Mutation, 30, 860-866.

Westergaard KB, Alsos IG, Popp M et al. (2011) Glacial survival may matter after all: nunatak signatures in the rare European populations of two west-arctic species. Molecular Ecology, 20, 376-393.

Wittwer CT (2009) High-resolution DNA melting analysis: advancements and limitations. Human Mutation, 30, 857-859.

Wittwer CT, Herrmann MG, Moss AA, Rasmussen RP (1997) Continuous fluorescence monitoring of rapid cycle DNA amplification. BioTechniques, 22, 130-131, 134-138.

Wittwer CT, Reed GH, Gundry CN, Vandersteen JG, Pryor RJ (2003) High-resolution genotyping by amplicon melting analysis using LCGreen. Clinical Chemistry, 49, 853-860.

Wyse Jackson MB, Parnell JAN (1987) A biometric study of the Arenaria ciliata L. complex Caryophyllaceae. Watsonia, 16, 373-382.

C.M., X.-D. D. and C.T.K. conceived the ideas for this work; All the contributing authors collected samples; X.-D. D. led the data analysis; C.M. and X.-D. D. led the writing.

\section{Data Accessibility}

DNA sequences for composite haplotypes C01-N02 in Table 4 are archived on Genbank accession nos 
JQ945739-JQ945758 inclusive. The final DNA sequence assembly used for genetic distance and phylogenetic analysis is deposited in FASTA format on DRYAD, doi: 10.5061 /dryad.s904k.

\section{Supporting Information}

Additional supporting information may be found in the online version of this article.

Figure S1. Maximum likelihood phylogenetic tree generated from recorded rps16 haplotype sequences and sister-group taxa using MEGA 5.0 (Tamura et al., 2011)*1.

Figure S2. Correlation between HRM $T_{\mathrm{m}}$ calculation in-vitro and in-silico.
Figure S3. In-silico simulation of SNP mutation sensitivity for HRM analysis using Arenaria ciliata rps16I haplotype $I 01$ as a wild-type template (352 bp length).

Table S1. Location and size of sample populations of Arenaria ciliata $(A c)$ and $A$. norvegica $(A n)$ used in High Resolution Melt Analysis.

Table S2. Results of in silico RFLP analysis carried out using NEBcutter (Vincze et al. 2003).

Please note: Wiley-Blackwell are not responsible for the content or functionality of any supporting information supplied by the authors. Any queries (other than missing material) should be directed to the corresponding author for the article. 